\title{
NARCOTICS ADDICTION AND ITS TREATMENT
}

\author{
Charles Winick*
}

Drug addiction is one pathology, whether it be regarded as a public health or psychiatric problem, which seems to have benefited comparatively little from new advances in knowledge over the last few decades. It is certainly a most complex condition in terms of prognosis and recovery rate. ${ }^{1}$ The hold of drugs on persons addicted to them is so great that it would be almost appropriate to reverse the old adage and say that opium derivatives represent the religion of the people who use them.

How many people are addicted to drugs is not reliably established. Addicts are hardly eager to be counted in a census, because the nonmedical use of addicting drugs is illegal and is considered immoral. It is usually estimated that there are some 60,000 addicts in the United States, based on the number of persons who have been in contact with law enforcement agencies. ${ }^{2}$ The figure of 60,000 is usually broken down into 50,000 opiate addicts, 5,000 marijuana users, and 5,000 addicted to opiate-like synthetics. ${ }^{3}$ One authority, however, estimates that there are three addicts who have not been in contact with the law for every one who has. ${ }^{4}$ This would suggest that the number of addicts is perhaps underestimated and that there are more than 60,000 .

Moralistic attitudes may extend into even scientific discussions and may be responsible for the sharply divergent recommendations made for coping with the addiction problem. Addiction is a serious illness, with frequently tragic consequences; but it is so linked in the minds of many with the underworld, which is the source of narcotics, that their attitude toward crime takes precedence over their attitude to disease. Another discouraged and frequently expressed attitude toward the needs met by addicting drugs is: "That humanity at large will ever be able to dispense with Artificial Paradises seems very unlikely." ${ }^{\circ}$ Americans' great interest in tranquilizing drugs which make them feel better is an example of how susceptible we are to the appeal of chemical influences on mood.

*B.A. I94I, City College of New York; M.A. 1949, Ph.D. 1950, New York University. Secretary, National Advisory Council on Narcotics; Director of Research, Narcotics Addiction Research Project; Consultant, United States Senate Subcommittee on Juvenile Delinquency; Lecturer in Psychology, Queens College. Research Associate, University of Rochester Studies in Drugs and Personality, 1952-53. Contributor to various social science periodicals.

${ }^{1}$ Berger, To Dispel the Nightmare of Narcotics, N. Y. Times Magazine, July 8, 1956, p. 13, col. r.

${ }^{2}$ See Cabinet Interdepartagental Comamittee on Narcotics, Report to tue President to (1956).

${ }^{3}$ Sec, e.g., Kolb, Let's Stop This Narcotics Hysteria, Sat. Eve. Post, July 28, 1956, p. 50.

"Col. Frank J. Smith, in Conferences on Drug Addiction Among Adolescents 93 (r953).

- Aldous Huxley, The Doors of Perception 49 (I954). 
AdDiction

The United Nations' World Health Organization has defined addiction inclusively: ${ }^{6}$

Drug addiction is a state of periodic or chronic intoxication detrimental to the individual and to society, produced by the repeated consumption of a drug (natural or synthetic). Its characteristics include: (I) an overpowering desire or need (compulsion) to continuc taking the drug and to obtain it by any means; (2) a tendency to increase the dose; (3) a psychic (psychological) and, sometimes, a physical dependence on the effects of the drug.

Addiction to narcotic drugs is usually pragmatically defined as the compulsive use of a habit-forming narcotic drug so that either self-control over the addiction is lost or the individual and/or the community are harmed. The use of a narcotic drug by itself is not addiction. There are older drug users, sometimes fairly wellestablished in the community, who work, maintain families, and have for decades regularly taken drugs.

The opiate addiction syndrome includes the separate but related phenomena of tolerance, habituation, and physical dependence. ${ }^{7}$ Tolerance is the decreasing effect on the user of repeating the same dose of a drug, or the need to keep increasing the dose as the drug is taken frequently over a long time-span. Habituation is the personality's emotional and psychological dependence on the drug in lieu of the more usual kinds of satisfactions. Physical dependence is the body's need to continue the drug in order to avoid the acute characteristics of the abstinence syndrome.

In the abstinence syndrome, the addict who is deprived of the drug he has been taking will show an almost schematic pattern of behavior which is a function of the patient and the length, strength, and nature of his addiction. ${ }^{8}$ Its intensity can be measured on a point scale. ${ }^{9}$ In an addict who has been taking morphine every day, a fairly predictable series of symptoms will set in if the drug is withdrawn. He will be restless about eight hours after his last "shot" and sleeps restlessly in about twelve hours. After twenty-four hours, the patient will lacrimate, yawn, vomit, sneeze, sweat, develop gooseflesh (the origin of the phrase "cold turkey"), pupil dilation, running nose, and have involuntary movements of his limb muscles ("kicking" is the addict's argot for ceasing his "habit"). Diarrhea, aches, some fever, rapid respiration, slightly higher blood pressure, increase in the white cell count, and many other symptoms may appear as the abstinence syndrome unfolds. These

\footnotetext{
"U. N. Expert Committee on Drugs Liable to Produce Addiction, Report 6-7 (World Health Organization Technical Report Series No. 21, 1950).

${ }^{7}$ See Clifton K. Himmelsbach and Lyndon F. Small, Clinical Studies of Drug Addiction: "Rossium" Treatment of Drug Adniction (U. S. P. H. Rep. Supp. No. 125, 1937).

${ }^{8}$ See Wikler, Clinical Aspects of Diagnosis and Treatment of Addictions, 15 Buld. Menningen Clinic I57 (I95I).

${ }^{\circ}$ See Himmelsbach, The Morphine Abstinence Syndrome: Its Nature and Trealment, 15 ANs. INr. MeD. 829 (194I); and Clinical Stusdies of Drug Addictions: Physical Dependence, Withdrawal and Recovery, 69 ARCH. INT. MED. 766 (1942).
} 
symptoms are usually at their agonizing peak between forty-eight and seventy-two hours after the last "shot" has been taken. From five to ten days usually are necessary before these manifestations of the abstinence syndrome disappear. Some lesser abstinence characteristics may continue for several months.

Heroin abstinence symptoms are likely to be analogous to, although more accelerated and more intense than, those for morphine. N-allylnormorphine (nalorphine) helps produce short abstinence syndromes within a quarter hour after being administered to opiate addicts. ${ }^{10}$ When given to nonaddicts, its effects are like those of a small dose of morphine. Nalorphine, thus, shows the presence of addiction within a half-hour, by producing typical symptoms of withdrawal, although it is not a legally binding test of addiction. There is no adequate laboratory test to confirm that a person is or is not an addict unless he exhibits withdrawal symptoms, which are then presumed to show that he had been taking drugs which have been abruptly withdrawn.

The administration of methadone prevents the appearance of symptoms of abstinence from most known analgesic drugs, and abstinence symptoms from methadone are milder than abstinence symptoms from the other drugs, which is why it is widely used in systematic withdrawal treatment of addicts. ${ }^{11}$

Abstinence from barbiturates produces its own very severe withdrawal symptoms, including insomnia and anorexia, within one day after the last dose of drugs. ${ }^{12}$ Most barbiturate addicts undergoing the abstinence syndrome have had at least one convulsion by the second or third day after their last dose, and some sixty per cent undergo a psychotic period during the fourth to seventh days of abstinence. These symptoms usually disappear within a week. Abstinence symptoms are not found in users of cocaine, marijuana, peyote, or benzedrine, because these drugs do not cause physical dependence.

\section{II}

\section{The Addict and Drugs}

The federal law defines narcotic drugs as opium derivatives (especially heroin and morphine), products of the coca leaves (especially cocaine), marijuana, and various synthetic opiates like demerol and methadone. In actual practice, patients are found to be addicted to a variety of drugs in addition to those mentioned in the law, such as the barbiturates. The federal hospitals admit individuals addicted to opiates, cocaine, marijuana, or peyote.

In the 1930's, morphine appeared to be the drug of choice among addicts. ${ }^{13}$ To-

${ }^{10}$ See Wikler et al., Precipitation of "Abstinence Syndromes" By Single Doses of N-allylnormorphne in Addicts, II FED. Proc. 402 (1952).

${ }^{11}$ See, Isbell, Meeting $A$ Growing Menace-Drug Addiction, Merck Report, July r95x, p. 5.

${ }^{19}$ See Isbell, Addiction to Barbiturates and the Barbiturate Abstinence Syndrome, 33 ANN. INT. MED. 108 (1950).

${ }^{13}$ See Michael J. Pescor, A Statistical Analysis of the Clinical-Records of Hospitaltzed Drug Addicts (U. S. P. H. Rep. Supp. No. 143, 1943). 
day, heroin is by far the most widely used drug. Price, income, regional, personality, ethnic, sex, length of addiction, previous medical history, availability of drugs, and age factors are linked with the selection of a given drug. Many persons who take heroin have previously smoked marijuana, but many marijuana smokers never go on to taking heroin. Addicts often experiment before settling on a drug which provides the kind of sensation they want.

Cocaine helps release aggressiveness and speeds up and activates the user, while heroin slows the user down. Marijuana's effects are sometimes described as being like the effects of alcohol, although its intoxication is more a condition of quiescence. ${ }^{14}$ Opium usually requires several hours before the effect of the "poke" makes itself felt, in the form of a languorous heightening of sensation. The price of addicting drugs varies from fifty cents for a marijuana "reefer," to three dollars for a heroin "fix," to as high as fifty dollars for a "tin" of opium.

Marijuana is usually taken by smoking "reefers," cocaine is sniffed in powder form or injected, heroin is generally injected into the veins, opium is smoked in a specially prepared pipe, and barbiturates are taken in pill form. If one drug is temporarily unavailable, the addict may use another opiate for which he has developed a crosstolerance. Some addicts used alcohol before taking drugs, and some drink after they stop taking drugs; but in the class system of addiction, the drug user usually looks down at the "wino" (alcoholic) and is reluctant to drink, except as a last resort.

A frequently found mixture is to take a stimulant and a depressant simultaneously. The "speedball," or mixture of cocaine and heroin, blends the shock power of cocaine with the extended afterglow of heroin and is widely used by experienced addicts to "go fast slow." Milder but related sensations are derived from taking benzedrine and barbiturates together, or smoking marijuana shortly before or after drinking alcohol.

Young people are probably likely to use marijuana, while opium is usually smoked by older persons. Opium is associated with a more sustained kind of sensation, and young people are not likely to seek this kind of "high." They are also not likely to have the funds necessary either to buy opium or to provide the free opium which usually constitutes the payment for the specialist "chef" who "cooks" it. Addicts have been using less cocaine in the last few decades because its effect is short-lived and it must be taken so frequently that it is expensive. Cocaine also may have some unpleasant after-effects.

To try to develop a picture of the "average addict" would be difficult, because the use of drugs is a dynamic function found in different kinds of people. The kind of person who becomes an addict varies from one region to another and from country to country. The United States and Germany would appear to have a high percentage of physician-addicts, although reliable figures are not available. In France

\footnotetext{
${ }^{16}$ See Reichard, Some Myths About Marihuana, Fed. Probation, Oct.-Nov. 1946, p. I5. However, many marijuana addicts are so afraid of being hypersensitized by the drug that they will not drive a car while under its influence.
} 
and England, the comparative incidence of addicts from the middle and professional classes is greater than in the United States, although this may be a function of our record-keeping methods, which do not show the middle or upper-class addict who can afford private treatment.

At least several weeks of experience with a drug are usually necessary for the development of an addiction. A fairly typical heroin addict, with a well-developed addiction, may take about five capsules a day. ${ }^{15} \mathrm{~A}$ user who has had to increase his dosage from the beginner's half "cap" or who takes at least one capsule a day is regarded as an addict for all practical purposes. A confirmed heroin addict may take as many as twenty-five capsules a day, with each capsule likely to contain an average of two per cent of heroin and ninety-eight per cent of sugar of milk. However, addicts seldom know how diluted the drug is, and they may exaggerate the amount they have been taking in order to get more drugs during the withdrawal treatment.

There are few pathognomic physical characteristics by which the opiate addict can be recognized as such. Scars and abscesses which result from intravenous injections of opiates are among the few helpful overt diagnostic characteristics. The cocaine or benzedrine addict may show pupil dilation, tachycardia, and tremulousness. It is difficult to recognize a marijuana smoker, although he sometimes has a characteristic facial flush. Opiates may be detected by analysis of an addict's urine for as much as ten days after the drug was last used. There may be emaciation from lack of food, both because opiates often diminish appetite and because the addict's money is being used to buy drugs. Little or no evidence exists to show that the continued use of any opiate causes permanent changes in the brain or central nervous system, or that it causes any change except the body's greater tolerance of the drug. There is no conclusive evidence on opiates' effect on life-span, although they have been said to shorten life. ${ }^{16}$

The person addicted to barbiturates may look slovenly and display aggressiveness and poor speech or motor control. Barbiturates differ from the other addicting drugs in that it is comparatively easy to get sleeping pills, whereas the other drugs are primarily dispensed through underworld sources. Barbiturate addiction appears to be increasing, and it is only within the last decade that barbituratism has been recognized as a "true" addiction. ${ }^{17}$

Some slight secondary effects of addiction remain even after the "habit" has been shed. Addicts who have not had drugs for years may experience a "taste" merely as a result of talking about drugs. They may exhibit some of the physical characteristics

${ }^{15}$ See Lambert, Report of the Mayor's Committee on Drug Addiction to the Hon. R. C. Patterson, Jr., Commissioner of Correction, New York City, 87 AM. J. PsycristrY 433, 471 (1930).

${ }^{16}$ See Kolb, supra note 3, at 50. Cutting, Morphine Addiction for Sixty-Two Years, I Stan. MED. Butl. 39 (1942), reports an eighty-four year old practicing physician who had taken morphine for sixty. two years.

${ }^{17}$ See Isbell, Acute and Chronic Barbiturate Intoxication, U. S. V. A. Tech. Bull. TB ro-76, Aug. I5, I951, p. 2. 
which had been associated with addiction, such as scratching, nauesa, and stomach pains.

Opiates make the addict feel good, and their effect is usually immediate. The effect of heroin begins to make itself felt while the needle is still in the addict's vein. One addict typically described the sensation as, "You're not afraid, you can explore anything, you feel great, stoned, never bored. Nothing's a hassle." Work, social, emotional, fantasy, family, sexual, and interpersonal problems may be solved -temporarily-by taking the drug. Addicts are often terrified of what awaits them in a nondrug situation, and this is responsible for many of their difficulties in remaining in treatment. The "medical addict" becomes addicted because he has grown used to the pain-relief provided by a drug which was originally given him for medical reasons.

The euphoria of the addict is a feeling of temporary well-being induced by the drug's suppression of discomfort or pain. ${ }^{18}$ The addict's "high" is a feeling of aloofness from current situations and a postponement of decisions or urgencies. The drug is the decision. It provides a feeling of security and self-sufficiency. It temporarily helps to establish self-confidence and quell any disturbing aggressiveness. The drug itself is so fulfilling that it becomes the center of the user's whole life.

Although some addicts initially feel that opiates make them more efficient and "normal," after the "honeymoon period," they are taking drugs primarily to avoid the symptoms of abstinence. Some students have emphasized the extent to which drugs make a user more efficient and bring him up to the level of normal behavior, while others dismiss this as a typical rationalization of addicts and feel that drugs make the addict lazy, sleepy, and inefficient. Recent work has suggested, however, that this apparent disagreement may be semantic: "normal" to the addict means gratification of "primary" needs-sex, hunger, pain-avoidance-in a direct way by the drug; ${ }^{19}$ but in releasing more stable patterns of reaction, the opiate may reduce the motivation to engage in socially productive activity.

Although there are physicians and others who have maintained successful careers while actively addicted to opiates for long periods, most addicts cannot continue to function in the community. The semisoporific effects of opiates make it all but impossible for the addict to function aggressively in any ordinary work-situation. So akin to sleep is the effect of an opiate that the addict refers to it as being "on the nod," "stoned," "out of this world," "half awake and half asleep." His ability to earn a living is also likely to be impaired because he has to spend so much time procuring his drugs that he may literally have no time to work. Addicts seldom

${ }^{18}$ See Reichard, Addiction: Some Theoretical Considerations as to its Nature, Cause, Prevention, and Treatment, I03 AM. J. Psychnatry 721, 722 (1947). Brown, The Effects of Morphitie Upon the Rorschach Pattern in Post-Addicts, I3 Ax. J. ORthopsychntry 339 (1943), found that morphine increased fantasy life.

${ }^{19}$ See Wikler, A Psychodynamic Study of a Patient During Experimental Self-Regulated Re-Addiction to Morphine, 26 Psychistric Q. 270 (1952). 
achieve vocational success, because their ability to consummate their frequently high aspirations and fantasies is likely to be impaired by self-neglect and their need to engage in self-defeating, self-hurting behavior.

The spectacular effects of opium on various writers are more attributable to the writers than to the drug, which has only a brief impact on inspiration. ${ }^{20}$ Opium is perhaps the one drug which can permit heightened creativity, because it does not make the user feel "knocked out." Jazz music is one of the few vocations which is presumably enhanced by drug use. The drug, which decreases technical ability but is believed by many musicians to be a spur to creativity, heightens empathy and makes the musician feel that "nothing's in the way" of his expression and that his perceptions are fresh and easy to translate into music, especially if he is playing a familiar or standard musical number. ${ }^{21}$ The specific drug used by the musicians is reflected in their music and is related to the degree of their acceptance by society. Alcohol was often used by early Dixieland musicians with their raucous rhythms, marijuana was linked with musicians playing the more sensitive and lighter swing music, and heroin use is associated with the complexities and emotional flatness of the "cool" music of today. Alcohol is a socially acceptable stimulant, and the Dixieland musicians were accepted by their society. The marijuana-smoking swing musicians of the I930's did not really "belong," and this process of alienation is felt most strongly in the "cool" music of today. This music is described by musicians as being "way out"- the same expression they use to describe the effect of heroin. The use of opiates is known to have ravaged the lives of many brilliant jazz artists, and the industry is determinedly trying to eliminate the use of drugs by musicians.

Although the action of a given drug is generally specific enough so that it can be described with precision, there remain many individual differences which are reflected in the user's reaction to the drug. Thus, morphine is a depressant, but in the widely-found "cat" reaction, the drug produces an excitatory effect. ${ }^{22}$ And how a drug may serve different purposes for the same user is seen, for example, in the case of the prostitute starting her career who takes heroin to deaden her responses to her customers, but also uses it to enable her to enjoy sexual activity with her "boy friend."23

${ }^{\circ}$ See M. H. Abrams, The Milk of Paradise, the Effect of Opium Visions on the Works of DeQuincey, Crabbe, Francis Thompson, and Coleridge (Harvard Honor Theses in English No. 7, 1934). Wagner, Coleridge's Use of Laudanum and Opitm, as Connected with his Interest in Coniemporary Investigations Concerning Stimulation and Sensation, 25 PsxchoANalytic Rev. 309 (1938), characterizes Coleridge's drug habit as an illness.

${ }^{31}$ Based on interviews by the author with seventy jazz musicians. However, two different studies of the effect of marijuana both reported a decrease in the musical abilities tested. Aldrich, The Effect of a Synthetic Marihuand-Like Compotnd on Musical Talent As Measttred by the Seashore Test, 59 U. S. P. H. REP. 43 I (1944); Williams et al., Studies on Marihuana and Pyrahexyl Compound, 6r U. S. P. H. REP. 1059 (1946). For the jazz musician as a seeker after liberation and individuality, see Esman, Jazz-A Study in Cultural Conflict, 8 American Imago 219 (195I); Warren, Jazz and Crime, I Chicago 26 (1954).

${ }^{22}$ See Brown, The Psychology of Drugs, in Modern Abnormat Psychology 6go (Mikesell ed. 1949).

${ }^{33}$ See Harold Greenwald, A Study of Deviant Sexual-Occupational Choice by Twenty New York Women, 6, 15 (unpublished Ph.D. thesis in Columbia University Library 1956). The author is grateful to Dr. Greenwald for permission to see an advance copy of this study. 


\section{III}

\section{Some Social Factors in Addiction}

The study of drug addiction represents almost a classic instance in which different social science and medical disciplines have each emphasized one facet of a complex problem. Anthropologists see addiction as a culture complex, sociologists report a situation in which social learning takes place, psychologists look for individual differences in addicts, physiologists observe a drug's specific bodily effect, psycho analysts note a pregenital addict personality structure, statisticians relate addiction to times of depression and war, psychiatrists find prepsychotic characteristics, experimentalists are worried about a lack of control groups in addict research. All of these approaches to addiction are valuable, and they all must be considered in any comprehensive approach to the study of addiction phenomena.

Sociological research has its own goals and should not be expected to explain the physiological and emotional mechanisms of addiction or why one person becomes an addict while his next-door neighbor who is also exposed to drugs will not become an addict. A recent study in Chicago suggests that an individual takes a drug like marijuana as a result of motives and dispositions which emerge in the course of experience, rather than on the basis of antecedent predisposition. ${ }^{24}$ An earlier study concluded that the drug user becomes addicted by realizing that the drug alleviates his withdrawal symptoms, after which he interiorizes his society's attitude toward addiction and thinks of himself as a "dope fiend."

Although the addict is often believed to be a solitary, there may be a great many social satisfactions which result from drug addiction. Heroin addicts usually are introduced to the drug by a friend "turning them on," which involves tying the upper arm with a stocking, belt, or necktie to expedite the injection of the drug into the vein by exposing the vein more clearly. For the first few weeks of using heroin, it is almost impossible for the addict to arrange the equipment he needs by himself. Even after he is a confirmed addict, the heroin user may enjoy socializing with other addicts and getting "on" together, although some addicts remain isolates.

The conversation of a group of addicts sometimes helps them to express themselves because they feel free to insult ("put down") each other. Drugs can permit a compliant person to express hostility within a framework of group acceptability. Crying, insults, and vigorous arguments are not uncommon in such situations, even though opiates usually stifle aggression. A favorite topic of conversation is the large number of prominent people, especially entertainers, who are said to be addicts. This aspect of the addict's mythology helps reinforce his image of himself as a member of an elite ("hip") in-group. The wide popularity of certain "bop" or "cool" expressions makes the addict feel that many people are sympathetic toward

\footnotetext{
24 Becker, Becoming a Marijuana User, 59 AM. J. Sociozogy 235 (1953). Elsewhere in this symposium, the social and psychological aspects of the narcotics problem are more extensively considered. Clausen, Social and Psychological Factors in Narcotics Addiction, infra 34-51.

${ }^{25}$ AlfRed R. Lindesaith, Opiate AdDiction (1947).
} 
him. The popularity since 1952 of "bop jokes," with their "cool talk," telescoping of reality, themes which are pronarcotics, antiauthority, and antisex, was hailed by many addicts as a sign that the larger society had begun to accept and need them. ${ }^{26}$

The drug user is creating a closed in-group where he "belongs" and where the ceremonies of the group and its illicit ritual help to reinforce the inadequacies and weak egos of the members of the group. Society's having outlawed drug taking serves to strengthen the masochistic ties which keep an addict in the group. Converting someone to drug addiction helps the addict feel less guilty about his own addiction, and he rationalizes this by reassuring himself that he is only giving his friend a "high" once. Another underlying motive for converting others is that there will be more heroin available if there are more addicts trying to get the drug, so that in case of an emergency shortage of drugs, there will be more drugs in circulation. ${ }^{27}$ Although they are traditionally out for themselves, in case of a temporary shortage of funds with which to buy drugs, addicts may help each other, and this is a related reason for developing new addicts.

Many legislators feel that the easiest way to treat narcotic addicts is to eliminate the "pusher," who buys his drugs from a jobber ("peddler") and sells to the addict consumer. The "pusher" is almost always an addict. Few "pushers" make any money out of selling drugs, in as much as they are generally not the prosperous bullies of popular belief, but persons who have such a low self-concept that even in an addict group of comparatively inadequate personalities, the only way in which they can feel important is to be wanted by the addicts whom they supply. The "pusher" is associated with several addict groups, the members of which are often constantly courting him in order to insure their supply. The "pusher" has such importance in an addict group that he is referred to as "the man." Even though he must constantly keep on the move to avoid police, he may deliberately come late to an appointment ("meet") and say that he has no heroin when he actually does have some, in order to prove how important he is to his customers.

The kind of gray subculture typified by the addict is common to prostitutes and jazz musicians, two occupational groups frequently associated with addiction. It typifies the condition of anomie, or being loosely integrated and rootless in a society. As the addict says, he belongs "nowhere." The society of other addicts provides a kind of social life for these otherwise unattached persons, bound together by the common ties of addiction and delinquent behavior. ${ }^{28}$ The addict has absorbed the values of his delinquent subculture and adopted its methods of solving problems by not facing the problems. The members of this group rationalize their difficulties

${ }^{20}$ The trend was documented in That Crazy Bop Joke Craze, Life, Sept. 29, 1952, p. 67. A typical "bop joke" was the story of the two addicts sitting in their apartment around 6 p.m. when they heard a knock on the door. They suspected the knock might be a narcotics agent, so they quickly hid their drugs in the cuckoo-clock on the wall. It was not the agent, but a friend, and they forgot all about leaving the drug in the cuckoo-clock. Around 9 p.m., the door of the clock opened very slowly, and the cuckoo appeared and very groggily asked: "Does anyone know what time it is?" (195I).

${ }^{27}$ See Zimmering et al., Heroin Addiction in Adolescent Boys, II4 J. Nervous \& Mental. Disease ig

${ }^{29}$ See Bingham Dai, Opium Addiction in Chicago (1937). 
in competing in the status system of the larger world outside by establishing criteria of their own.

Among these criteria is knowledge of argot, which constitutes almost a secret language. This language is so different that several key terms mean exactly the opposite of their usual meanings. In the last few years, addicts have begun using "bad" to mean good, and the superlative form of this is "terrible," meaning excellent or great. The highest form of praise one can use is, thus, to say that something is "terrible," or "ridiculous," or "crazy."

Addicts are often not able to enter into usual family and community responsibilities. They may not marry; and if they do marry, the marriage is likely not to be viable, or they may convert their wives to addiction. There is an unusually high number of common-law relationships among addicts. Even though such relationships may last for years, an actual marriage poses responsibilities and problems which addicts are not too eager to accept. The expense of spirit as well as of money needed to support a "habit" is likely to corrode marriage and family relationships.

There is some evidence to show that minority groups are overrepresented in the addict population. ${ }^{29}$ Minority groups are likely to be especially alert to the stresses and strains of living. Difficulty in facing up to these stresses and strains helps many to get on the road to addiction. Drugs represent one way in which members of minority groups may channel the aggressiveness which they traditionally have difficulty in expressing. A study of American Indians has shown that the members of a tribe most drawn to peyote had difficulty in identifying either with the tribe or with the world outside the tribe. ${ }^{30}$ This kind of marginal personality is drawn to drugs, which provide one way of feeling integrated and important.

Even in a delinquent or minority milieu, the person likely to be an addict is the person who has the most ambiguous status or who is most removed from the group's norms. ${ }^{31}$ Of the different groups in the prostitute subculture, the procurer is almost always a drug addict, not only because he is bored with his leisure, but because he enjoys no status and is universally despised. ${ }^{32}$

\section{IV}

\section{Some Psychological Factors in Addiction}

Many an addict, in taking drugs, is, in effect, telling his family and society, "You have done everything possible to deny me. I won't die, but I'll show you how close

${ }^{29}$ See Alan S. Meyer, Soctal and Psychological Factors in Opiate Addiction 30-50 (1952).

${ }^{30}$ Spindler, Personality and Peyotism in Menomini Indian Acculturation, 15 Psxchuatry 151 (1952).

${ }^{31}$ Addicts often cite various persons who were so far ahead of their group or society that they resorted to drugs as a symbol of their advanced thinking. The addict, who often has feelings of inferiority, can assure himself of his superiority by his identification with these "advanced" persons. Some addicts like to point out that Sherlock Holmes's regular use of cocaine by hypodermic injection did not interfere with his extraordinarily brilliant feats of detection. The famous phrase, "Quick, Watson, the needle," is not, however, found in the novels by Arthur Conan Doyle, but in William Gillette's play, Sherlock Holmes (1899), in which Holmes injects the drug into his arm whilc on stage, after Dr. Watson has brought Holmes his hypodermic needle.

${ }^{32}$ See Jess Stearn, Sisters of the Nigrt 55 ( 1956$)$. 
to death you have brought me. The only way in which I can go on is to take drugs." Addicts in treatment sometimes say, "If I don't get on, I'll kill myself or somebody else-would you prefer that?" Many addicts, especially those from relatively good backgrounds, rationalize their addiction by explaining that nobody understood them. Rebellion and experimentation are related needs found in some addicts.

Recent work on nonaddicts has suggested that personality factors help determine the kind of patient who will get consistent pain relief from a placebo, or dummy tablet which consists of pharmacologically inert substances, like lactose. The person who responds favorably to a placebo is also likely to prefer opiates to other drugs. ${ }^{33}$ The power of subjective factors in determining the effect of a drug is seen in the finding that a placebo is most effective when stress on the individual is greatest. ${ }^{34}$ This placebo research suggests not only that there is a kind of person who is extremely sensitive to the pain-deadening effects of chemicals and who is predisposed to anticipating pain-relief, but that this individual prefers opiates to other drugs. It is this reaction, writ large, which we find in the opiate addict. Further placebo research may throw new light on the kind of personality which is likely to become "addiction-prone."

Heroin addicts often are proud of the scars caused by their needle, which they may exhibit with pride. Many seem to create situations in which they may be caught by the authorities, thus masochistically calling attention to their suffering and blaming others for it.

Taking the drug enables addicts to achieve that which they cannot achieve in ordinary life, especially if their ability to defer gratifications is poorly developed. Their attitude toward the drug is ambivalent, since they both need the drug and resent it for enslaving them. The words which addicts use to describe drugs are likely to carry a strong negative loading-e.g., "junk," "crap." By using such strong taboo words, they are expressing their fear of the drug, their participation in something illegal, and their attitude toward the society which has been responsible for their having to take drugs. Addicts often display their nonreality leanings by engaging in magical thinking. 35

One of the elements of the drug lore which addicts exchange with each other is that they can tell just before a full-blown "habit" is about to develop, by various physical symptoms. This will alert them, they feel, so that they can stop taking drugs before becoming addicted. The drug user realizes this is a rationalization only after it is too late for him to do anything about it.

Addicts often display a kind of grim insight into their friends and associates, as in the case of the saxophonist who accurately diagnosed another musician-addict who had a disturbed Oedipal relationship: "He's carrying a horn for his mother."36

There appears to be no one kind of psychiatric diagnosis which is common to

${ }^{83}$ See Felsinger et al., Personality and Reactions to Drugs, 157 A. M. A. J. IIr3 (1955).

${ }^{\mathrm{a}}$ Beecher, The Powerful Placebo, 159 id. at I602 (1955).

${ }^{35}$ See Fort, Heroin Addiction Among Young Men, i7 Psychiatry, 251, 256 (1954).

${ }^{80}$ Case treated by Dr. Jack Krasner. 
drug addicts. All kinds of people can and do become drug addicts. The psychiatric classification of the addict does not determine the progress of his addiction. A patient with a severe character disorder may recover from an addiction in a short time, while a patient with a mild neurosis may be unable to stop taking drugs. In each case, the drug fulfills a specific function in the personality economy of the individual, and it is this function which determines how difficult it will be for the addict to shed his drug. There have been a good many psychiatric classifications of types of addicts, but these classifications often place the majority of addicts in a catchall category, like "psychopathic."37

The addict is responding to underlying personality problems of great complexity. His difficulties in achieving interpersonal and heterosexual satisfactions may be linked to his narcissism and difficulties on the Oedipal level. Identification with the parent of the same sex may be poor, and the parent of the opposite sex is often either overprotecting or rejecting or both. The addicts preoccupation with family relationships is seen in his frequent use of "daddy" to talk to or refer to males. The widespread use of "baby" in talking to or in referring to females is another indicator of the addict's regression and preoccupation with family. The supplier of drugs is often called "mother."

The drug often takes the place of sexual activity, although addicts may engage in either homosexual or heterosexual activity. The hypodermic needle often provides a kind of sexual play, with the addict inserting the needle into his vein, waiting for the blood to come up, injecting a small amount of heroin as he then forces the blood back by letting up his pressure on the hypodermic. He may do this several times, before finally injecting the rest of the contents of the hypodermic into the vein.

The heroin injection is described by addicts as causing a sexual glow. Just before receiving the "shot," the addict often gets a feeling of prepleasure, localized in the bowel area. Rado has called taking drugs a kind of alimentary orgasm, which has strong oral orgastic components. ${ }^{38}$ Simmel has pointed out the strong autoerotic and masturbatory components in the addict's preoccupation with his body. ${ }^{30}$ Brill has studied the extent to which the language of addicts is erotized. ${ }^{40}$

Addicts derive erotic pleasure from scratching themselves. The addict usually prefers to scratch one part of the body, often the face. Sexual behavior in addicts is often what Freud called polymorphous perverse: its aims may be centered around

${ }^{37}$ See Felix, An Appraisal of the Personality Types of the Addict, roo AM. J. PsychnTru 462 (1944); Michael J. Pescor, The Kolb Classification of Drug Addicts (U. S. P. H. Rep. Supp. No. I55, 1939).

${ }_{38}$ Rado, The Psychoanalysis of Pharmacothymia, 2 Psychonnalytic Q. I (1933).

${ }^{30}$ Simmel, Zum Problem von Zwang und Sucht, in Bericht U Ber Den V. AlzGeMeinen Artzlichen Kongress Fur Psychotherapie IN BADEN-Baden 26 (1930); and Morbid Habits and Cravings, I7 Psychonnat.ytic Rev. 48I (1930).

${ }^{\circ}$ Brill, Some Notes on Dynamics and Treatment in Narcotic Addiction, 23 J. Psychiatric Socist Work 67 (1954). The author is indebted to Mr. Brill for several stimulating discussions on problems of addiction. 
what are usually considered forepleasure activities. ${ }^{41}$ Addicts often engage in sexual activity passively and are concerned with their own and not with their partner's gratification. Like the "cool" jazz solos with which it is popularly associated, addict sexual activity seldom reaches a climax.

There are some aggressive addicts who take drugs as one way of expressing aggressiveness toward themselves, others, and the community, although the addict's relation to his drug is often said to be based on a passive oral dependence on supplies from outside. ${ }^{42}$ It is compared to an infant's passively ingesting so much of its reality in the form of milk, and taking such gratification while giving nothing in return.

Addicts often refer to themselves as "cats," perhaps because cats are symbols of passivity. The pet cat traditionally does not play with others, is relatively aloof, and provides a kind of passive companionship. The cat owner has to court the cat, as opposed to the more outgoing and affectionate dog.

Drug addiction sometimes has elements of manic depression, with a drug-induced artificial "mania" which alternates with a state of depression after using the drug. It is this increasing depression which the addict tries to meet by taking more drugs at decreasing intervals. Paranoia and obsession-compulsion have also been linked with addiction. ${ }^{43}$ Gross has reported the difficulties of most addicts in effective identification, especially identification with morality. ${ }^{44}$ Some few addicts may be schizophrenic, although most addicts are not clinically schizophrenic, even if they may have some schizoid characteristics. It is possible that some addicts would have developed schizoid episodes or personalities if they had not taken to drugs.

Psychiatrically sound persons who accidentally become addicts represent a small percentage of the total addict population. ${ }^{45}$ The more usual kind of "addictionprone" person who becomes addicted would probably require psychiatric help, even if he had not taken up the use of drugs. His need for immediate gratifications would probably lead to a behavior pathology. The first time an individual tries a narcotic drug, he is usually sick. Many of those who try heroin or marijuana once or twice do not take it again. Yet, there are those who overcome the initial sickness reaction and go on to become addicts. The degree of tension with which these individuals can cope is perhaps linked to the development of their addiction. A drug which immediately eliminates tension appeals to people who cannot face problems realistically.

Whatever the addict was like before taking drugs, his behavior becomes more regressive and self-centered once he has become addicted. His affect is flattened,

11 Sigmund Freud, Three Contributions to the Theory of Sex 51 (19io).

"See, e.g., Otto Fenichel, The Psychoanalytic Theory of Neurosis 377 (I945).

${ }^{13}$ See Glover, Common Problems in Psychoanalysis and Anthropology, I2 BRIT. J. MED. Psxch. I09 (1932); and On the Aetiology of Drug Addiction, I3 INT't J. Psychonnarysis 298 (I932).

"Gross, The Psychic Effects of Toxic and Toxoid Substances, I6 INT'L J. Psychoanalysis 425 (I935).

${ }^{4}$ Lawrence Kolb and W. F. Ossenfort estimate that $3.8 \%$ of the addict population is psychiatrically normal, but this figure may be high. See The Treatment of Drug Addicts at the Lexington Hospital, 31 So. MED. J. $9 \times_{4}$ (1938). 
and his favorite word of praise is frequently "cool," to mean a kind of ultracontrolled behavior, with a lack of warmth or emotional expression. A person who does not "belong" is called "uncool," which is a very denigratory expression.

The drug is taken to satisfy inner needs of the premorbid personality, although each drug has a specific effect, and personality and behavior will change as a result of the drug. The investigator can, thus, only surmise what the premorbid personality might have been like, although such surmises are probably often accurate. Some students have seen a disagreement between the psychiatric viewpoint of addiction as a symptom of an underlying personality difficulty and the pharmacological viewpoint of addiction as a specific kind of bodily dependence linked to the drug of choice, which has a specific effect. This disagreement is perhaps based on the psychoanalyst's use of metaphor and observation, as opposed to the pharmacologist's precise language and research design. The psychoanalyst looks for large patterns, while the pharmacologist is more likely to look for measurable effects. These two approaches actually complement each other, since the addict is a person with certain personality characteristics who happens to have selected this way of coping with his problems for a variety of reasons, of which he is usually unaware. Not the least of these reasons is his access to a social group in which drug use was both practiced and valued. He takes one drug rather than another because it provides satisfaction for him.

Other people with exactly the same kind of personality substratum never become addicts and select other means of expression for their basic conflicts. Thus, the family constellation and personality of the addict are often not only similar to the schizophrenic's, but they are also similar to those of some members of the American Communist party, which would appear to be a different kind of group. ${ }^{40}$ On the other hand, it is difficult to generalize about family background, because a study of addicted physicians, for example, reports that they were raised in a relatively congenial home situation. ${ }^{47}$ Data on the family which are derived from direct questioning of the patient may not be too reliable as clues to the real dynamic of the family and should be regarded with caution. Recent research with a control group of paired nonaddicts has shown that both groups had behavior pathology, but only the one group became addicted. ${ }^{48}$ Wikler has remarked that the addict is meeting the basic human need of activity directed toward realizable goals by engaging in

${ }^{4}$ See Krugman, The Role of Hostility in the Appeal of Communism in the United States, 16 Psychistry 253 (1953), who found that the parents of some American Communists he had studied were psychodynamically similar to those of many addicts.

${ }^{17}$ Pescor, Physician Drug Addicts, 3 Diseases of THE Nervous System I73 (1942). Addicts are usually so disturbed that it is almost safe to generalize that their family backgrounds probably have serious interpersonal disturbance.

${ }^{48}$ Gerard and Kornetsky, Adolescent Opiate Addiction: A Study of Control and Addict Subjects, 29 Psychitric Q. 457 (1955). Aldrich, The Relationship of the Concept Formation Test to Drug Addiction and to Intelligence, roo J. Nervous \& Mental Disease 30 (1944), found no differences in conceptual thinking of postaddicts and nonaddicts. 
a continuous pursuit of drugs, which itself becomes an activity with its own sense of accomplishment and its own self-contained goals. ${ }^{49}$

\section{V}

\section{Treatment at the Federal Hospitals}

The devoted research and treatment activities of the federal narcotics hospitals have provided the knowledge on which almost all treatment of drug addiction is based. In spite of the never-ending flow of addict patients, there is usually little waiting, once the addict has decided to go to the hospitals at either Lexington, Kentucky, or Fort Worth, Texas, depending on where he lives. The Lexington hospital is the world's major center exclusively devoted to the study of addiction.

Some idea of the dimensions of the treatment problem can be gained by a study of the flow of patients to these hospitals. ${ }^{50}$ At the present time, Lexington and Fort Worth have 1,574 beds reserved for addicts. In 1955, there were 3,638 addict admissions to these hospitals. Since 1935 , when federal facilities became available, they have admitted over 35,000 addicts, in 54,000 separate admissions. About forty per cent of the patients have been through the hospital before and are "repeaters." Twothirds of the patients are voluntary, but only twenty-five per cent of these voluntary patients stay the recommended minimum period of four and one-half months. Hospitalization is currently mandatory only if the addict has gone to prison for violating the federal laws, or if he has received a suspended sentence on the condition that he submit to treatment.

The Lexington treatment includes various ancillary rehabilitation services. The patient gets a thorough physical examination and psychiatric screening. Physical withdrawal from drugs has been called the least important part of the addict's treatment and is accomplished in the most humane way possible in order to minimize pain and heighten rapport between the patient and his physician. ${ }^{51}$ After a period of drug stabilization, the synthetic analgesic methadone is administered orally, instead of the opiate administered up to several years ago. Decreasing doses of methadone usually accomplish withdrawal in ten days. Withdrawal in barbiturate addiction is more complex and is accomplished by stabilizing the patient on a barbiturate, often pentobarbital, and then decreasing the dosage, usually for a period of up to a month. ${ }^{\text {22 }}$

After the withdrawal period, vocational activities, recreation, and some kind of psychotherapy have a major role in the treatment program, which ideally lasts from

${ }^{10}$ Wikler, Rationale of the Diagnosis and Treatment of Addictions, 19 ConN. STATE MED. J. 3 (1955).

${ }^{20}$ See Subcommittee on Improvements in the Federal Criminal Code of the Senate Committee on the Judiciary, Treatment and Rehabilitation of Narcotic Addicts, S. REP. No. 1850, 84th Cong., $2 \mathrm{~d}$ Sess. (1956).

${ }^{81}$ See Vogel, Isbell, and Chapman, Present Status of Narcotic Addiction with Particular Reference to Medical Indications and Comparative Addiction Liability of Newer and Older Analgesic Drugs, ${ }^{3} 8^{1}$ A. M. A. J. rorg ( 1948 ).

${ }^{\circ 2}$ See Isbell, supra note II. 
four to six months. Investigations conducted at the hospital have revealed that addicts do not regain physiological normality for some six months after withdrawal from drugs. ${ }^{53}$ Every attempt is made to re-educate the patient in a therapeutic environment, and his other ailments are treated. Most patients do not receive effective psychotherapy because of limitations of personnel and time.

Relapse to the use of drugs seems to be an integral part of the addiction syndrome. Although exact statistics are not available, well over one-half the patients who have gone through Lexington have probably gone back to the use of drugs. It is difficult to get exact figures, because such figures must take into account the patient's ability to stay out of the hands of the local authorities.

The addict is likely to return to the use of drugs if his original motives for taking drugs are not changed and he returns to the same environment. As a rule of thumb, a former addict who has not used narcotics for eighteen months is considered not to be an addict in terms of government practice. ${ }^{54}$ There is such an onus attached to taking drugs that it is somehow assumed that an addict's relapse is due to forces other than the operation of a disease process. Wikler notes that the twenty per cent of Lexington patients who were abstinent from drugs over an extended period of time compares favorably with the recovery rate from other chronic ailments, like diabetes mellitus or pulmonary tuberculosis. ${ }^{55}$ The diabetic who went back to the hospital for diet and insulin regulation would not be regarded with suspicion, while the addict is regarded with suspicion if he relapses. This attitude toward addiction is based on the erroneous belief that the addict's illness is reversible at his will. The addict would stop if he could, but he cannot.

Another reason for the relapse rate is that once withdrawal has been accomplished, many patients feel stronger, are eating well, and feel good enough to regard themselves as "cured." Most such persons leave the hospital before the recommended minimum treatment period and return to the use of drugs, since their feeling of health is likely to be illusory and the old craving may return and cause them to backslide. A common rationalization for becoming "hooked" again is, "I took one shot just to prove I can stay off it." This is magical thinking, because one "shot" may lead to another. An investigator who conducted a study of the prognosis for recovery of federal hospital patients decided that "guarded" and "poor" prognoses covered most cases for practical purposes, and that a "good" prognosis could be discarded."56 Such a conclusion should not be regarded with pessimism, however, but as an indication that inadequate preparation for the world outside, coupled with inadequate follow-up, leads to a return to drugs.

Contact with former patients to find out what they are doing is difficult, because the patients may not want to cooperate or to be reminded of their past. The only

\footnotetext{
${ }^{83}$ Pescor, Time Element in the Treatment of Drug Addiction, 99 AM. J. Psychiatay 438 (I942).

see Reichard, The Narcotic Addict as a Custodial Problem, 5 Prison Worto 12 (1943).

ts Wikler, supra note 8 , at 164 .

${ }^{60}$ Pescor, Prognosis in Drug Addiction, 97 AM. J. Psychiatry 1419 (1941).
} 
patients on whom thęre are reliable data are those on probation, who are required to report regularly to probation officers. The great distances which separate the hospitals from many communities make communication difficult. The hospitals do not know what becomes of two-thirds of their patients, and they are prohibited from communicating with the former patients who are at the hospital on a confidential basis. ${ }^{57}$

One of the difficulties of judging the effects of psychotherapy at these hospitals is that therapy is seldom given to voluntary patients, because they do not remain at the hospital long enough to benefit from it. Thus, much of the information available is based on the therapy given involuntary patients. Time and personnel limitations often interfere with the psychotherapy goal of providing socially acceptable goals for the postaddict, whether voluntary or involuntary.

Some of the advantages of a centralized facility like Lexington represent the other side of the coin of some disadvantages. The concentration of a large number of addicts in one place may lead to less-experienced addicts acquiring sophistication about drugs from some of the more-experienced patients.

Many former Lexington patients blame their return to drugs on the treatment they received at the hospital. They complain about the limited psychiatric and social service facilities and about having to undergo a long waiting period before admission. There is no doubt that personnel limitations make some kinds of treatment impossible, but in general, these hospitals have been remarkably effective in their attempts to remove the patient from drugs and in trying to prepare him for the world outside. The hospitals can hardly be held responsible for their shortage of psychiatric and social work personnel or if patients leave before the treatment process runs its full course. They are even less responsible for difficulties in communication and inadequacies of the programs of the states and communities to which the addict returns.

\section{VI}

\section{Community Fachlities}

The federal hospitals provide the major facilities for treatment of addicts, because very few state mental hospitals or city institutions will accept addicts. Private hospitals are generally quite expensive. Both public and private hospitals are usually reluctant to accept addict patients because they require special facilities, because they fear that addicts' treatment is difficult, or because they think that addicts may disrupt or contaminate the staff and patients. Addicts in a hospital may overwhelm the hospital personnel with requests and demands. These contacts with addict patients have been called ". . . exhausting, unrewarding, and frequently

\footnotetext{
${ }^{57}$ Senate Committee on the Judiciary, supra note 50, at $x 6$. Some pilot work has been done on offering limited casework services to postaddicts who had been at Lexington, suggesting that such services are feasible if the former addicts' initial suspicions are allayed.
} 
revulsive ... for both the individual and group who deals with the addicted person." ${ }^{\text {"68 }}$

Many of the difficulties in treating addicts stem from communities' own ambivalence about drug addiction. Many communities and individuals have a kind of horrified fascination toward addicts. A study of a recent film dealing with narcotics revealed that many normal subjects who saw the film had a remarkable ability to recall its details of the physical aspects of addiction, while they had entirely missed the very laudable antinarcotics theme of the film. ${ }^{59}$ Too many individuals see the addict as a kind of demonic "dope fiend," and a necessary concomitant of any effective treatment program is a community attitude which accepts the addict as a sick person with a serious disease.

There is not one community in the United States which has an integrated program of hospitalization, psychiatric treatment, and rehabilitation for addicts. Especially lacking is any program for posthospital and postwithdrawal care of the addict. Detroit and Chicago are the only cities with any rehabilitation program. Only one community (New York) has a narcotics hospital, and it is only for addicts under twenty-one. In view of all the attention given to the "drug menace," it is startling to find that community action is so halting.

Even if there is a desire to cope with the problem, community action on addiction must wait on the availability of suitable personnel and hospital facilities, and there is a lack of both. For example, in May 1954, the Michigan legislature passed the Ryan Act, which permits the Health Department to petition the courts for commitment of addicts for rehabilitation purposes. As of November 1955, however, there was no hospital available for these purposes. ${ }^{60}$

The ex-addict returns to his home from a federal hospital under difficult circumstances. He has no money and is back in the same community which helped to spawn his addiction, with the additional handicap of being known as a former addict. Employers are often wary about hiring a person who has been an addict, and since he is often unskilled to begin with, his legitimate employment is likely to be difficult. His family situation is likely to have been strained by his long absence. Social agencies are often reluctant to help the former addict in his attempt at rehabilitation, especially in the vocational retraining which he is likely to need. His nonaddict friends may be suspicious of him, and his addict friends may be all too available.

If he has difficulties in finding work, his feelings of inadequacy may be revived. Few people in the community know that the federal narcotics hospitals are not jails, and they are likely to regard the ex-addict as some kind of ex-convict. Some kind of "halfway house" for milieu therapy, to help bridge the gap between federal hospital and effective social functioning, would appear to be a crucial lack in existing treatment programs.

\footnotetext{
${ }^{68}$ Raskin et al., A Suggested Approach to the Problem of Narcotic Addiction, a paper prescntcd to the American Psychiatric Association, May 2, 1956, p. 14.

${ }^{50}$ Winick, The Effects of a Film on Its Audience: The Man with the Golden Arm, a paper presented to the Annual Meeting, American Association for Public Opinion Research, May 25, 1956.

${ }^{60}$ Sce Herbert A. Raskin, Interim Activity Report on Narcotics Clinic, Detroit r8-19 (i955).
} 
Many addicts are reluctant to go to Lexington or Fort Worth at all, because a hospital located thousands of miles from home is not an inviting prospect. Some addicts are afraid to leave their home towns, jobs, and families for almost a halfyear, and some are unable to leave their community because they are already on parole. If regional or local hospitals were established, they would get many of these patients. Narcotics wards in state or city hospitals, with specially trained personnel, would make it even easier for the addict. In case of relapse, it would be infinitely easier for the addict to go to a relatively nearby facility and to know that it were available whenever he should need it. This would also make him feel that the community had a genuine interest in helping the former addict to recover, by its concern with his problems of health, diet, family, housing, education, and other realities of living a drugless life. Since many addicts are members of minority groups who have experienced discrimination, it is important to help them feel that it is possible for them to achieve self-actualization and integration in the community. There is some evidence to show that community religious facilities can be very useful in rehabilitation of the addict. ${ }^{61}$

One approach to treating addicts might be modeled after the successful experience of several states and countries in treating different kinds of delinquents. ${ }^{62}$ After a period of re-education, and vocational rehabilitation, the patient is assigned to a volunteer sponsor in the community who is always available to the patient. This kind of permissive authority relationship may help provide a success experience with authority for the addict, who is likely to have had a bad experience with parental authority, which is perhaps partly responsible for his antiauthority behavior in taking drugs. The sponsor would be available to help the former addict to solve his problems of living, as they arise, and would see that the addict did not have to go back to the same social group which originally introduced him to drugs. The former addict can be strengthened to stay away from drugs to the extent to which he has access to friendly nonaddict individuals and groups. It is difficult, however, for even friendly groups to understand that the addict sometimes relapses and "kicks" several times before his susceptibility to drugs is completely quenched.

A related method of therapy is the kind of mutually-supportive group therapy offered by Narcotics Anonymous (NA), developed at Lexington in I947 and started in I949 by Daniel Carlsen, an ex-addict who spent a good part of his life in an almost single-handed attempt to help addicts to help themselves. ${ }^{63}$ Its approach is similar to that of AA (Alcoholics Anonymous), and it has branches in many cities. It has used the "buddy system" successfully, by assigning an older member

ol See East Harlem Protestant Parish, New York, The Problem of Narcotics (1956).

${ }^{02}$ The Big Brother and related groups in the United States represent a good example of how effective this approach can be. See Drson Carter, Sin and ScIence (1955), for how effectively this has worked in rehabilitating prostitutes.

${ }^{03}$ Daniel Carlsen died August 19, 1956. He required eight trips to Lexington to cure him of his addiction. He had been an addict for twenty-five years and spent nine of those years in jail. See Our Way of Life (n.d.), a pamphlet issued by the New York NA chapter. 
of the group as a sponsor of each new member. NA only accepts members who are off drugs, and its meetings often provide constructive and reassuring opportunities for an ex-addict to hear his own problems discussed with other ex-addicts who have undergone the same sensations and difficulties. It is typical of our society's attitude toward addiction that NA has never been able to raise funds in the community. Each attempt to raise money has been unsuccessful because the people approached were convinced that the money would be used to buy more drugs for the NA members! NA, however, has made a good start toward gaining public confidence and providing a useful facility for ex-addicts. It has underlined how important it is for ex-addicts to get reassurance and support from others in the community.

Among the proposals now being considered to facilitate the community care of addicts is the suggestion that Lexington be used only for withdrawal, with rehabilitation to be conducted in the addict's own community. Another suggestion would reserve a specific number of beds at Lexington for patients from each state, in exchange for which, the states would develop an after-care program for the addicts, who would be compulsorily admitted to Lexington.

\section{VII}

\section{Some Problems in the Treatment of Addicts}

Even if community hospital facilities were available, there are some addicts who cannot accept the hospitalization which is the recommended treatment. The nonhospital treatment of a patient with a current addiction presents a number of very difficult problems to a physician, who is violating the law if he issues a prescription for drugs. The addict is likely to be experienced at simulating symptoms so that he will be able to get drugs to alleviate his "pain," or in cajoling the physician into giving him drugs "just this once." The physician is likely to worry about the patient stealing valuables or prescription blanks. Psychiatrists are likely to recall the very few addict "cures" and to be reluctant to accept addict patients. psychiatrists do not realize that relapse to the use of drugs is to be expected in treatment.

Psychotherapy with addicts poses many problems in establishing a therapeutic relationship. Drug addicts have seldom developed close interpersonal ties with others and are likely to have transferred their expectations of rejection by others to the therapist. They leave the therapy situation if they feel that it will merely duplicate their disappointment in other people, and this may help account for the extremely high percentage of therapy failures. Another reason for poor results is that the addict may enter the therapy situation in the belief that he will be able to get some drugs by convincing the therapist of his great need for them. Many psychotherapists will only accept an addict patient if he is off drugs, because of difficulties in coping with the addict when he is on drugs.

\footnotetext{
es Marie Nyswander, The Drug Addict as a Patient (1956), has an extremely thorough discussion of treatment procedure from the point of view of the physician and community.
} 
Even if the addict gets into psychotherapy, he presents special problems, because addicts are patients who act out, or gratify repressed desires or unconscious tensions by social behavior which is not reality-oriented and which brings unhappiness and suffering. Many therapists have difficulty coping with patients who engage in acting-out behavior, and the special kind of antisocial syndrome common to addicts is perceived by some therapists as threatening to their own security system. The addict is a person who experiments with different kinds of satisfactions in order to raise his self-concept. The addict's freedom from inhibitions and his "thrill seeking" may be threatening to some therapists, who may have unconsciously absorbed their society's moralistic attitude toward the sickness of addiction. The therapists' inhibitions against delinquent behavior are acquired relatively late in their own socialization process and may, thus, be shaken by the addicts' own delinquent behavior. The addict-patient is likely to be extremely alert to any such attitudes on the therapist's part and to respond to this implied censure, even though the addict is often a passive, nonaggressive patient. Psychiatrists working with criminals have found their ability to work with the patient is often impaired because they have absorbed their society's attitude toward criminals, and this unconscious moralizing interferes with the therapy. In as much as it is possible that the therapist may regard as most likely to be cured the kind of patient who most resembles himself, his orientation toward an addict-patient's cure is likely to be doubtful, and the addict may pick up these cues from the therapist.

Psychiatrists and psychotherapists in private practice, who should be in a relatively favorable position to conduct psychotherapy with addicts, have had almost complete failure. There have been only a very few psychotherapy success experiences. Group psychotherapy with the mothers of addicts has been tried experimentally, with disappointing results, but future groups may have greater success. Group psychotherapy has been successfully attempted with the mothers of schizophrenics, and the possible similarity between the mothers of schizophrenics and of addicts suggests this as an area for future experimentation.

Where depth-psychotherapy has been applied on a voluntary basis, as in the New York Narcotics Addiction Research Project, it was determined that some addicts seem accessible to psychotherapy. This project provides voluntary ambulatory psychoanalytic treatment at little or no cost. The preliminary project data collected to date suggest that there may be relatively few special hazards for the therapists who treat addicts in private practice. It has also established that some addicts are interested in obtaining treatment and that successful treatment seems possible for some of these patients, who are staying in therapy and appear to be making progress. The great majority of the addicts who made contact with the project, however, did not follow through, for reasons which have not been determined. But since the project has been under way for slightly more than a year, which is a relatively short time in terms of the psychoanalytic treatment of addicts, it can be tentatively suggested that these preliminary findings are not discouraging, especially in view of 
many of the participating therapists' comparative lack of experience with addict patients.

A Detroit municipal psychiatric clinic, established several years ago to help the addict on a purely voluntary basis as an out-patient facility, got only thirty-four voluntary patients in three years. ${ }^{65}$ The Detroit clinic had the familiar pattern of missed appointments, irresponsibility, and apathy on the part of the addict-patients. The Chicago voluntary clinics, established to provide medical counseling facilities for addicts, report a generally weak motivation for treatment and frequent patient instability and unpredictability. ${ }^{66}$ Many others who have attempted to work with addicts in a voluntary treatment situation have concluded that they can be relied on only to be unreliable and that this is part of their dynamic.

In spite of these experiences of failure in psychiatric treatment, there are reasons for believing that some addicts should be good risks for psychotherapy. Some are very verbal about their condition and enjoy talking about themselves. They are used to being very aware of their perceptions and sensations. ${ }^{67}$ The therapy situation offers an opportunity for masochistic gratification by expiating guilt through reliving suffering.

Working at Lexington, Johnston had fairly good results with group therapy. ${ }^{08}$ Others, working with ambulatory, voluntary-therapy groups of addicts in an urban setting, have reported great difficulty in keeping their group together. Group therapy has the advantage of providing a constructive situation in which the addict can be helped toward socialization in the world outside the therapy situation, by working through his feelings about the other members of the therapy group.

The many failures and relapses found in voluntary therapy with addicts have led many students to look askance at this kind of treatment, whether it be voluntary commitment to a federal hospital, voluntary admission to a community facility, or voluntary psychotherapy. The reasons given by addicts themselves for voluntarily seeking treatment are perhaps often to be regarded with some skepticism..$^{00}$ The patient may have such a strong "habit" that he needs a large amount of the drug to get "high," and after treatment, he can start all over again with a minimum dose. He may have lost his source of drugs, have no money, or may want to spite someone or avoid arrest. In general, however, a patient who is serious about submitting to a voluntary cure should be highly motivated and have a relatively good prognosis, since recovery depends so completely on the patient's desire to stay away from drugs. In one large-scale study, addicts who had had voluntary treatment were



${ }^{00}$ Ill. Dep't of Public Heatth, Medical Counseling Clinics for Narcotics Addicts (1953); Boshes et al., Management of the Narcotic Addict in an Outpatient Clinic, 113 AM. J. PsYchatrY 158 (1956).

${ }^{67}$ See Fort, supra note 35, at 254.

${ }^{68}$ See Johnston, An Experiment in Group Pyschotherapy with the Narcotic Addict, in MaNAGement op AdDictions 322 (Podolsky ed. I955).

${ }^{B D}$ See Lambert, supra note 15.
} 
able to remain off drugs for longer (2.2. years) than addicts who had involuntary treatment (1.8), on the average. ${ }^{70}$

Some students of addiction point to the comparatively few voluntary patients who complete the Lexington program or any other voluntary treatment program and urge that all treatment should, therefore, be mandatory. Even studies in private voluntary treatment show the importance of remaining for the full treatment period in relation to subsequent relapse. ${ }^{71} \mathrm{~A}$ mandatory patient at Lexington is required to stay for the whole treatment program and usually is placed on probation or parole following his release. Thus forcibly reminded of the power of the law, mandatory patients are presumably better able to withstand the temptations of drugs, although the threat of punishment is no deterrent to the many probationers who go back to drugs. Addicts, however, tend to think of any compulsory treatment, even in a hospital, as having penal overtones which they want to avoid.

Experience in a variety of treatment situations has shown that it is possible to conduct treatment with patients attending treatment on a mandatory basis. Under such conditions, it is possible for the therapist to establish a relationship with his patient. An authoritarian setting for treatment sometimes even helps the patient to get started into the treatment process and makes progress possible. A court can force a patient into a therapy situation, but once he is in it, a good therapist may be able to achieve a satisfactory relationship with the patient.

In discussions of both voluntary and involuntary treatment, it is important to understand the relation between remission and cure. The word cure is to be used with great care in discussion of addiction. ${ }^{72}$ It should not be used to mean temporary relief from physical dependence on a drug, because "cure" conveys the impression that the underlying cause of the addiction is being dealt with and there is total abstinence from the addicting drug. Any "cure" of a psychiatric illness in which the basic problems are not worked through may only lead to a situation in which the individual goes back to his original symptoms or to substitute symptoms. "Cure," in most diseases, means that the sick person has recovered completely and can resume his usual activities. If a person has been taking an addicting substance in moderation before becoming addicted, we should expect that he could go back to moderate use of the substance after the "cure" had been accomplished. But with drugs, this is all but impossible, so that terms like "successful treatment" and "total abstinence" are more realistic than "cure." There are, however, some ex-addicts who have been off drugs for many years who gradually tapered off their intake, after they "kicked" the "habit," until they completely lost their "yen." Although

${ }^{70}$ Mrchaet J. Pescor, Follow-Up Study of Treated Narcotic Drug Addicts (U. S. P. H. Rep. Supp. No. X70, 1943).

${ }_{71}$ Knight and Prout, A Study of Results in Hospital Treatment of Drug Addiction, I08 AM. J. PsychuATRY 303 (195r), suggest that the patients who did not relapse stayed in the hospital an average of 5.4 months, as compared with an average of 3.3 months for all cases studied. However, Pescor, supra, note 53 , in his follow-up study of Lexington patients, found no significant correlation between the length and effectiveness of treatment.

${ }^{73}$ See Reichard, supra, note 18. 
addiction is a reflection of underlying personality, the addict's recovery from his addiction does not depend on his recovery from any underlying psychiatric condition, which might take many years, but on his feelings about the drug itself and his ability to substitute other patterns of adaptation for the drug, which is the addict's whole system of adaptation. He must be aware of other possible patterns and be ready to accept them before he will give up something so satisfying as drugs.

On the basis of present hit-or-miss methods of record-keeping, it is not known how many "cures" addicts undergo, especially since there is a paucity of data on self-treated or nonpublic hospital patients. One study of voluntary patients at a New York municipal hospital reported an average of four "cures" per addict. ${ }^{73}$ It is possible that the patient who has treatment at a federal hospital is from a different socioeconomic status and has attitudes toward addiction and "cure" which differ from those of the private patient. ${ }^{74}$ The number of "cures" undergone by these two groups might, thus, differ considerably.

A study of teen-age drug users at the height of a recent addiction upsurge reports that only eighteen out of 313 were re-admitted to a hospital for drug use, ${ }^{75}$ but these patients are too young for any definitive determination of how long their addiction will last, since an addiction may last for a lifetime. Older studies report the addict to be between thirty and forty years of age, who has had a "habit" for from five to fifteen years. ${ }^{76}$ The kind of person now becoming an addict is much younger. $\mathrm{He}$ is in his twenties and has been addicted perhaps a year or less by the time he comes in contact with the authorities. ${ }^{7 \pi}$ These differences in the age and the length of the "habit" of addicts of an earlier period, as compared with the newer generation of addicts, may lead to a more hopeful recovery rate. Some of these adolescents and young adults should be relatively amenable to treatment. They are often likely to be aware of social and cultural demands and to be able to express overt anxiety, which should help them in psychotherapy. However, a severe personality problem usually starts early enough so that it can be well embedded by the teens.

Many physicians know of addicts who have cured themselves by the "cold turkey" method, going into seclusion while they undergo the extremely painful and cruel abstinence syndrome. Although definite statistics are lacking, many addicts, perhaps reflecting their need to suffer, believe that there is a greater percentage of cures in this group than with any other method. One explanation for this is that

\footnotetext{
${ }^{73}$ Lambert, stipra note 15 , at 471 .

${ }^{75}$ Knight and Prout, supra note 71, report that the seventy-five private patients they studied are from middle-class or better-than-average homes and began using drugs at a comparatively late age (37.2).

${ }^{75}$ New YoRk City Mayor's Committee on Drug Addiction, Interim Report, Druo Addiction Among Teen Agers (195I).

${ }^{76}$ Edward C. Jandy and Maurice Floch, Narcotic Addictjon as a Factor in Petty Larceny in Detrort (Detroit Bureau of Governmental Research Report No. 145, I937); Knight and Prout, stipra note $7 x$.

${ }^{77}$ See New York City Mayor's Committee on Drug Addiction, op. cit. supra note 75. Elsewhere in this symposium, the peculiar problem of the juvenile addict is more extensively discussed. Chein and Rosenfeld, Juvenile Narcotics Use, infra 52-68.
} 
the addict who is willing to undergo the rigors of "cold turkey," which addicts frequently discuss among themselves, has a stronger motivation to recover than does the addict who enlists outside authorities and facilities. The addicts who undergo "cold turkey" seldom do so deliberately, but because they have run out of either money or drugs, or because they want to avoid becoming known to the authorities. Some addicts feel so bad after a "cold turkey" experience that they go right back to drugs. It is impossible to know how many addicts have cured themselves in this way, although there may be many who have. There are addicts who stop taking drugs because their life situation changes, but addicts have difficulty in selftreatment for the same reason that a neurosis can seldom be self-treated: most people continue to live within the framework of their established patterns of behavior, and they cannot see their own blind spots.

\section{VIII}

\section{ConcLusion}

There can be no single program for the elimination of an illness as complex as drug addiction, which carries so much emotional freight in the community. Cooperative interdisciplinary research and action, more local community participation, training the various healing professions in the techniques of dealing with addicts, regional treatment facilities, demonstration centers, and a thorough and vigorous post-treatment rehabilitation program would certainly appear to be among the minimum requirements for any attempt to come to terms with this problem. The addict should be viewed as a sick person, with a chronic disease which requires almost emergency action.

The study of the dynamics of addiction is a relatively new field. We must study the successes in the treatment of addiction to find out how they were achieved. Schizophrenia and juvenile delinquency used to be regarded as hopeless conditions until new methods were found to reach schizophrenics and juvenile delinquents. New methods for the treament of addiction can also be found, and they will help to bring the study and treatment of addiction out of the penumbra. 